\title{
Simplified Design Criteria for Very High Temperature Applications in Generation IV Reactors
}

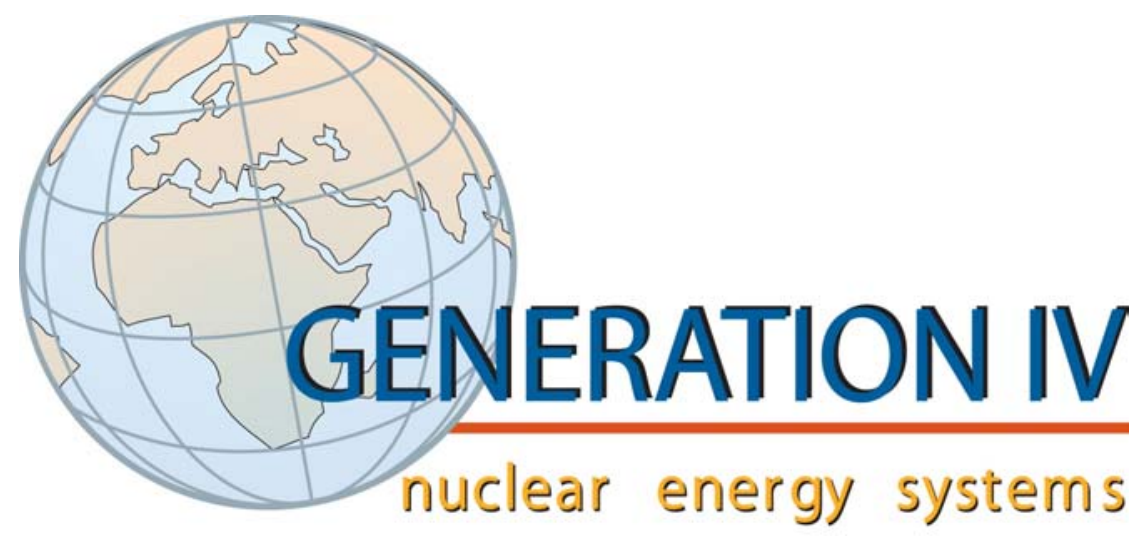

R.I. Jetter

T. E. McGreevy

Oak Ridge National Laboratory

Revision 1

December 6, 2004 


\title{
Simplified Design Criteria for Very High Temperature Applications in Generation IV Reactors
}

\author{
R.I. Jetter \\ T. E. McGreevy
}

Revision 1

Published December 6, 2004

Prepared for

Office of Nuclear Energy Science and Technology

Prepared by

OAK RIDGE NATIONAL LABORATORY

Oak Ridge, Tennessee 37831-6285

managed by

UT-BATTELLE, LLC

for the

U.S. DEPARTMENT OF ENERGY 


\section{TABLE OF CONTENTS}

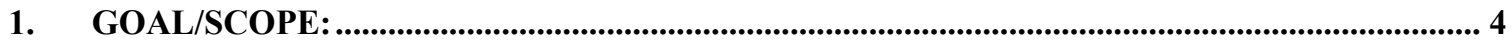

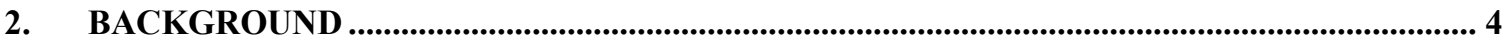

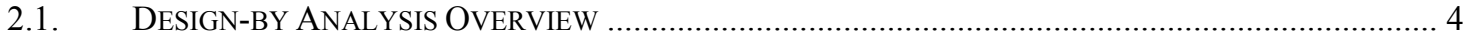

2.2. ElEVATED TEMPERATURE DESIGN CRITERIA ............................................................. 5

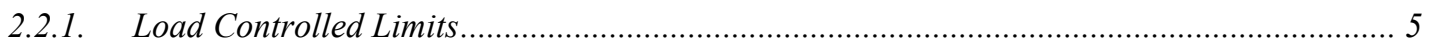

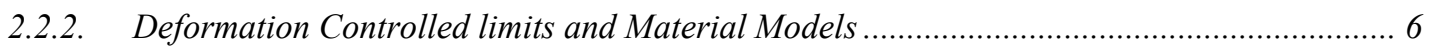

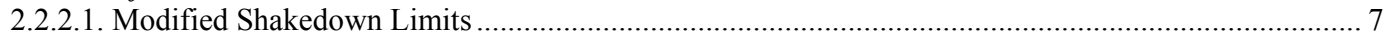

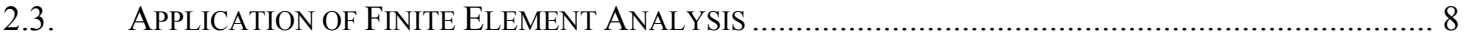

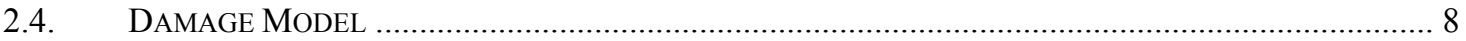

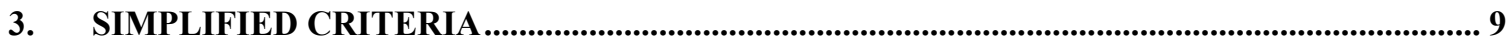

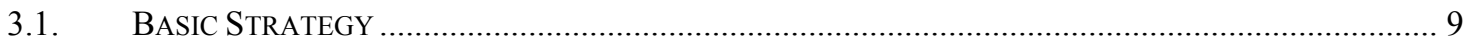

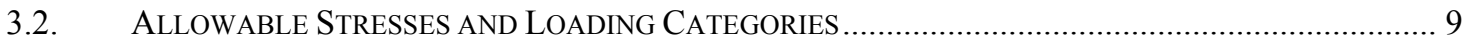

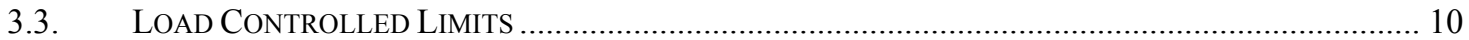

3.3.1. Reinforcement of Openings and Nozzle Loads ................................................... 10

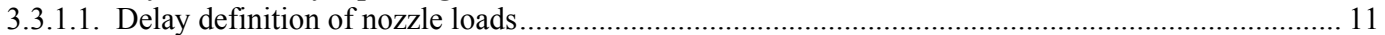

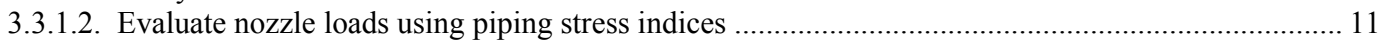

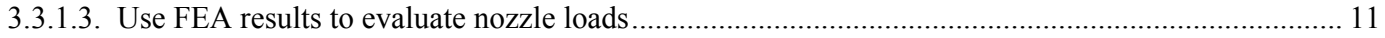

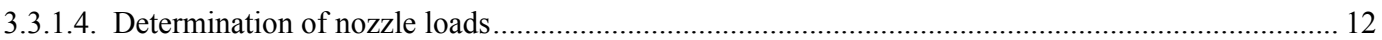

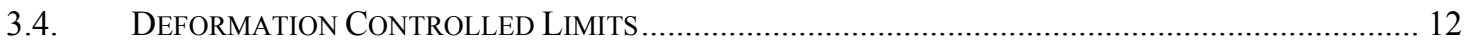

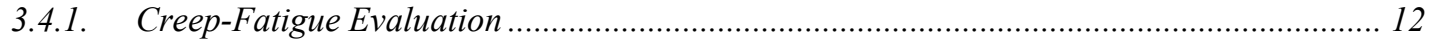

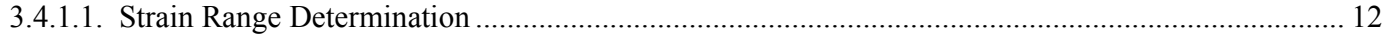

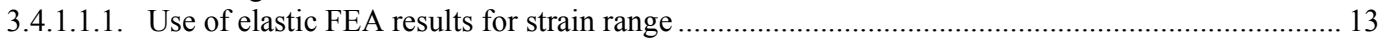

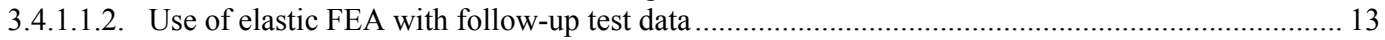

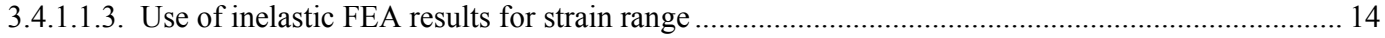

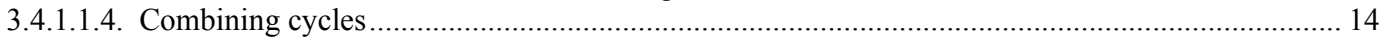

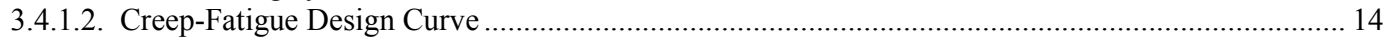

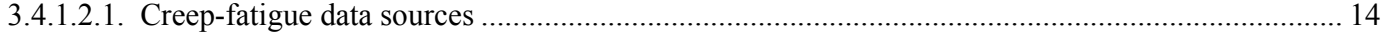

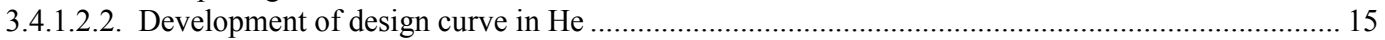

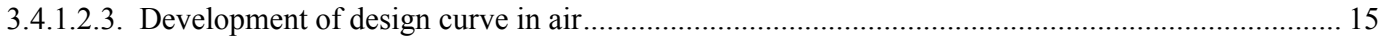

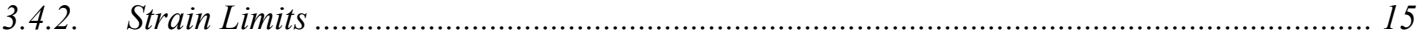

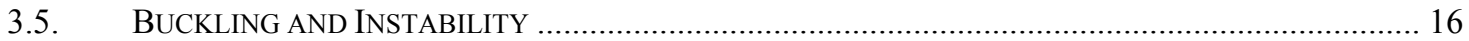

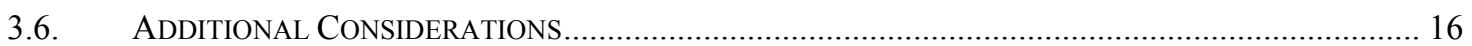

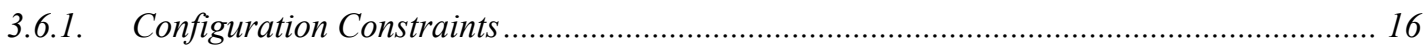

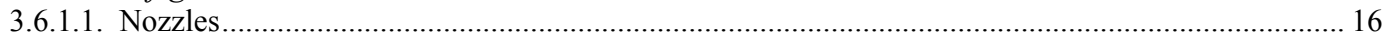

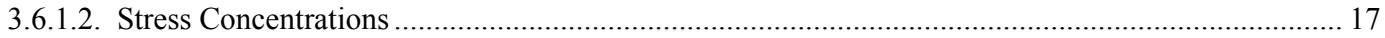

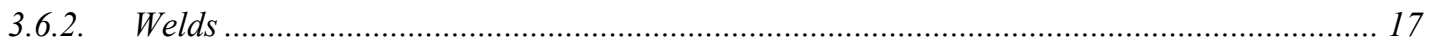

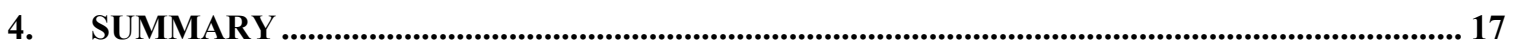

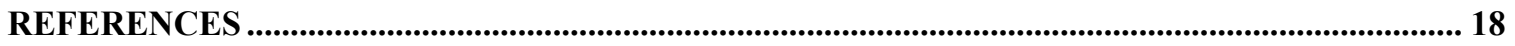

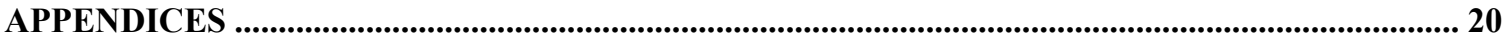

APPENDIX A - SIMPLIFIED CRITERIA SUMMARY ................................................................... 21

APPENDIX B - ALLOWABLE STRESS VALUES ................................................................... 24

APPENDIX C - CREEP-FATIGUE DESIGN CURVES ..................................................................... 28

APPENDIX D - ISOCHRONOUS STRESS/STRAIN CURVES ......................................................... 29 


\section{LIST OF TABLES}

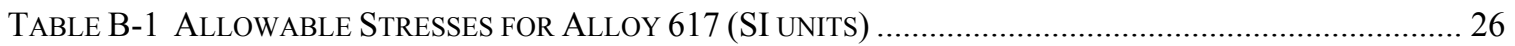

Table B-2 Allowable Stresses for Alloy 617, continued (SI UNITS) .............................................. 27 


\section{LIST OF FIGURES}

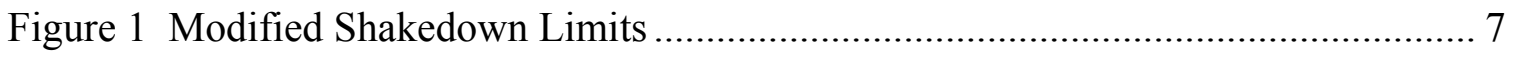

Figure B-1 Stress Rupture Curves for Alloy 617..................................................... 24

Figure B-2 Allowable Stress Levels for Alloy 617 ...................................................... 25

Figure C-1 Creep-Fatigue Design Curve for Alloy $617\left(950-1000^{\circ} \mathrm{C}\right)$............................. 28

Figure D-1 Average Isochronous Stress-Strain Curves for $927^{\circ} \mathrm{C}\left(1700^{\circ} \mathrm{F}\right) \ldots \ldots \ldots \ldots \ldots \ldots . . . . . .29$

Figure D-2 Average Isochronous Stress-Strain Curves for $982^{\circ} \mathrm{C}\left(1800^{\circ} \mathrm{F}\right) \ldots \ldots \ldots \ldots \ldots . . . . . . . .30$ 


\section{Goal/Scope:}

The goal of this activity is to provide simplified criteria which can be used in rapid feasibility assessments of the structural viability of very high temperature components in conceptual and early preliminary design phases for Generation IV reactors. The current criteria in ASME Code Section III, Subsection NH, hereafter referred to as NH, (and Code Case N-201 for core support structures) are difficult and require a complex deconstruction of finite element analysis results for their implementation. Further, and most important, times, temperatures and some materials of interest to the very high temperature Generation IV components are not covered by the current provisions of NH. Future revisions to $\mathrm{NH}$ are anticipated that will address very high temperature Generation IV components and materials requirements but, until that occurs interim guidance is required for design activities to proceed.

These simplified criteria are for design guidance and are not necessarily in rigorous compliance with NH methodology. Rather, the objective is for criteria which address the early design needs of very high temperature Generation IV components and materials. The intent is to provide simplified but not overly conservative design methods. When more rigorous criteria and methods are incorporated in $\mathrm{NH}$, the degree of conservatism should obviously be reduced.

These criteria are based on currently available information. Although engineering judgments have been made in the formulation of these criteria they are not intended to require additional development or testing prior to implementation as a tool for use in conceptual and early preliminary design.

Appendices are provided herein that contain useful information. The simplified methods were developed specifically with Alloy 617 in mind; however, they could be applied for the same intended purpose for other materials such as $9 \mathrm{Cr}-1 \mathrm{Mo}$, Alloy $800 \mathrm{H}$, etc.

However, supporting design curves, stress allowables, and isochronous curves may/were not available at this time for temperatures of approximately $1000^{\circ} \mathrm{C}$. Appendix $\mathrm{A}$ is a brief summary of the Simplified Methods that follow. Appendix B contains charts and plots of allowable stress values for Alloy 617. Appendix C contains the suggested creepfatigue design curves for Alloy 617 at $950-1000^{\circ} \mathrm{C}$, and Appendix D contains isochronous stress-strain curves for Alloy 617 at $927 \& 982^{\circ} \mathrm{C}$.

\section{Background}

\subsection{Design-by Analysis Overview}

Historically, the basic criteria framework for Class 1 nuclear components was developed in the 1950's and 1960's before the growth of computer technology made possible the common use of computer aided analysis methods, particularly finite element analysis. As such, criteria, referred to as "design by analysis", were developed to more specifically deal with "high localized and secondary bending stresses" than were (are) considered by Section VIII, Div 1 and Section I. Conceptually, these design by analysis criteria involve 
three basic steps in the determination of applicable stresses and their evaluation by comparison to the allowable stresses for the particular stress category.

The first step in the design by analysis methodology is to separate the structure into "free bodies" in equilibrium with externally applied loads. The resultant stresses, averaged and linearized in accordance with the rules, are categorized as "primary" stresses. The basic characteristic of a primary stress is that it is not self-limiting. Primary stress is a stress developed by the imposed loading which is necessary to satisfy the laws of equilibrium between external and internal forces and moments. Below the creep range, if yield is exceeded throughout the cross section, the resulting deformation is only limited by the strain hardening characteristics.

The next step, sometimes referred to as interaction or discontinuity analysis, is to apply forces and moments to the boundary cuts of the free bodies to restore structural compatibility. The resultant stresses, appropriately averaged and linearized, are categorized as "secondary" since they satisfy an imposed strain pattern rather than being in equilibrium with an external load. Their basic characteristic is that they are selflimiting. There can be localized yielding that shakes-down to elastic action.

The final step is determination of "peak" stresses typically associated with local stress concentrations and localized thermal stresses. The characteristic of a peak stress, which in Code terminology is the stress that is added to the primary plus secondary stress field, is that it causes no significant distortion. Peak stresses also result in no net resultant, i.e. if the geometry reconfigures, the peak stresses go away.

\subsection{Elevated Temperature Design Criteria}

The elevated temperature design criteria of $\mathrm{NH}$ were developed in their basic form in the late 1970s. The same stress categories and symbols described above were retained at a conceptual level, but instead of primary, secondary and peak, the criteria are subdivided into "load controlled" analogous to primary stresses, and "strain controlled" analogous to secondary and peak stresses. The deformation controlled category is further subdivided into strain limits and creep-fatigue evaluation. Because of the continuing deformation and redistribution of stress and strain due to creep, the elevated temperature design criteria are significantly more complex than the criteria for temperatures below the creep temperature range.

\subsubsection{Load Controlled Limits}

The rules for primary or load controlled stresses at elevated temperature are similar to those below the creep range with several exceptions. At elevated temperatures the allowable stresses are time dependent and thus a function of load duration. Also, due to strain redistribution effects, the primary bending stress must be modified by a shape factor function prior to being combined with the primary membrane stress components. The criteria are similar in that for elastic analysis, both are based on stresses determined in equilibrium with the external loads. However, whereas ASME Code Section III Subsection NB also permits the use of plastic analysis for the evaluation of load controlled stresses, NH does not. Below the creep range, failure under load controlled 
stresses can be associated with collapse of the structure. However, in the creep regime, there is an additional failure mechanism associated with rupture due to applied stresses that can be independent of collapse mechanisms.

\subsubsection{Deformation Controlled limits and Material Models}

There are two routes in NH to satisfying deformation controlled limits. What might be considered the fundamental approach is through a time dependent inelastic analysis wherein the stress and strain history at critical locations throughout the component is computed as a function of time. To implement this approach, constitutive relationships are required which model the time dependent and independent flow characteristics of the material and their dependence on prior loading sequence. Developing these behavioral relationships is a major task and has been a focus of significant R\&D activity. A number of years ago a format for these relationships and the supporting data were developed for most of the materials and temperature ranges currently covered in NH. However, for the principal material, time and temperature of interest to the very high temperature Generation IV components and materials, including but not limited to Alloy 617 for times up to 60 years and temperature to $1000^{\circ} \mathrm{C}$, this work remains incomplete. Application of this format is complicated by the observation that for previous models, separation of elastic/plastic and creep response probably won't apply for the above conditions in very high temperature Generation IV components and materials. Furthermore, even if the behavioral models and failure theory, to be discussed later, were currently in place in $\mathrm{NH}$, the inelastic analysis route does not lend itself to the above noted objective of "... rapid feasibility assessments of the structural viability of very high temperature components in conceptual and early preliminary design phases."

The other route in $\mathrm{NH}$ to satisfaction of deformation controlled limits is by means of elastic analysis. Sometimes referred to as screening rules, the concept was to have a simpler methodology than the full inelastic analysis which would not require a detailed modeling of time dependent flow characteristics. If the presumably simpler screening rules could not be satisfied then the designer could resort to the more difficult inelastic analysis criteria. However, in an effort to avoid over conservatism and to more representatively model time dependent structural behavior, the elastic analysis rules themselves (the ' $A$ ' and ' $B$ ' tests) have turned out to be significantly more complex, as described in the following paragraph, than the corresponding rules in Subsection NB where creep is not a factor.

An example of this relative complexity is the rule(s) in Appendix T of NH entitled "Satisfaction of Strain Limits Using Simplified Inelastic Analysis". Although outwardly similar to the NB limits on primary plus secondary stress intensity range $\left(\mathrm{P}_{\mathrm{L}}+\mathrm{P}_{\mathrm{B}}+\mathrm{Q}\right)$ in that both involve primary and secondary stress limits, the conceptual basis is different. Whereas the NB limit is based on shakedown to elastic behavior, the NH limit is based on limiting ratcheting and insuring the presence of an elastic core stress. The primary plus secondary stress term in NB is the range of a single parameter which is represented by the linearized portion of the total stress field from an FEA result. The NH limit, on the other hand, requires the separate tabulation of the maximum primary stress during the design life (with the factored primary bending stress), and the secondary stress range during the design life. Further, there are stresses normally considered secondary, and not 
generally determined from equilibrium conditions, which are considered primary in the application of certain $\mathrm{NH}$ rules. Examples are pressure induced secondary stresses and thermally induced membrane stresses which are classified primary in the evaluation of most, but not all, deformation controlled limits. The significance of this is that "parsing" of FEA results to determine stress categories, particularly at geometric discontinuities such as nozzles with three dimensional load variations, is a major problem in the use of FEA to satisfy NB requirements, and its application in NH can only be more difficult.

\subsubsection{Modified Shakedown Limits}

A useful concept in elevated temperature design is the creep regime equivalent of the twice yield strength shakedown criteria which is the basis of the primary-plus-secondary stress limit in Subsection NB. Shakedown in the creep regime is illustrated conceptually in Figures 1(a) and (b). Figure 1(a) is a plot of stress vs. strain and Figure 1(b) is a plot of stress vs. time for the same loading conditions. The strain controlled loading shown in this example starts at an initial value of zero and increases past the hot yield strength to a stress level of $\sigma_{1 \mathrm{H}}$ at which point the strain is held constant at $\epsilon_{1}$ and the stress relaxes to $\sigma_{2 \mathrm{H}}$. At this point the strain is cycled back to zero (the equivalent of a shutdown cycle in this example) and the stress cycles from tension to a compressive value of $\sigma_{2 \mathrm{C}}$. If there is no yielding during the shutdown cycle, when the strain is cycled back to $\epsilon_{1}$ the stress will cycle back to its value before the shutdown cycle, $\sigma_{2 \mathrm{H}}$. Again, holding the strain constant at $\epsilon_{1}$, the stress relaxes to $\sigma_{3 \mathrm{H}}$. If the strain is again cycled back to zero, the stress will again cycle from tension to compression at $\sigma_{3 \mathrm{C}}$ and if there is no yielding the stress will return to $\sigma_{3 \mathrm{H}}$ when the strain is cycled back to $\epsilon_{1}$. Thus, if there is no yielding on the shutdown cycle, the stress level at the hot end of the cycle will just follow the stress relaxation curve. As can be seen from Figures 1(a) and (b), the allowable stress range for which there is no yielding is bounded by the cold yield strength, $S_{y C}$ and the hot relaxation strength $S_{r H}$ at the end of the design life. In accordance with NH and NB practice, $S_{y C}$ is given by $1.5 S_{m}$ at the cold end of the cycle. For convenience, lacking values of $S_{r H}$ for Alloy 617, it is assumed that $S_{r H}$ can be conservatively approximated by the value of $S_{t}$ for the full design life. If there is yielding during the shutdown cycle, then the concept of a creep regime equivalent of the twice yield strength shakedown criteria is not applicable.

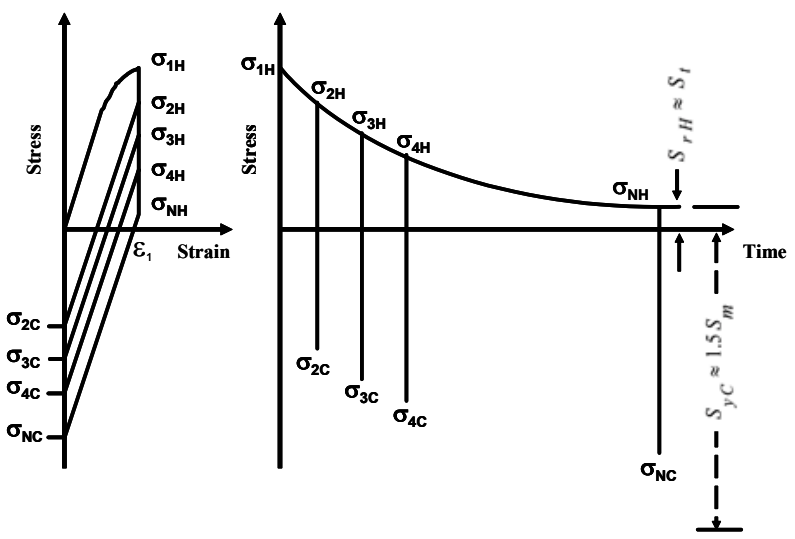

$\begin{array}{ll}\text { (a) Stress vs. Strain } & \text { (b) Stress vs. Time }\end{array}$

Figure 1 Modified Shakedown Limits 


\subsection{Application of Finite Element Analysis}

As discussed above, the conceptual framework for both the low and high-temperature elastic analysis design criteria is based on free body equilibrium analysis and interaction analysis. Early computer programs essentially automated the hand analyses, which were based on shell analysis, that were the conceptual framework for the criteria. This evolved to shell element finite element analysis (FEA) dealing primarily with axisymmetric geometries and, eventually, the widespread current application of solid element FEA capable of full three dimensional modeling of both loading and geometry. While current practice provides a comprehensive picture of the total (primary-plus-secondary-pluspeak) stress field, it does not readily lend itself to stress categorization as did early analytical approaches. This is clearly demonstrated by the current ASME Code task to develop guidelines for processing FEA results for assessment of Code stress limits. Initiated five years ago and now in its 18th revision, this 29 page document (3) mainly addresses procedures for stress linearization and doesn't specifically address stress classification. The document provides the warning that the FEA model might not be sufficiently detailed to provide accurate local peak stresses and also notes "Engineering judgment will always have to apply for the final decisions on appropriate SCL/SCP orientation depending on whether the intent of the assessment is for primary, primaryplus-secondary, or fatigue limits," where SCL and SCP refer to $\underline{\text { Stress }} \underline{\text { Classification Line }}$

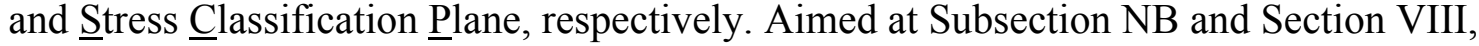
Div 2, the proposed document doesn't address guidelines for separating and factoring certain stress components before recombining them to determine the particular stress intensity quantities required by $\mathrm{NH}$.

\subsection{Damage Model}

Another difficulty in NH is the criteria used to assess cyclic life. Quoting from (4), "It is generally recognized, both by Code developers and researchers worldwide, that the current linear damage accumulation rule for creep-fatigue is incorrect and inadequate, particularly at higher temperatures and longer times. Various improvements, such as those based on ductility exhaustion and damage rate concepts, have been proposed, but none have been backed by sufficient R\&D to allow their adoption as a replacement for linear damage in $\mathrm{NH}$. These several shortcomings will have to be remedied for Generation IV systems."

In the linear damage accumulation rule as defined in $\mathrm{NH}$, damage is accumulated in two summations: continuous cycling fatigue damage in a Miner's rule hypothesis and creep damage in a time fraction summation. The potential interaction effects are accounted in a creep-fatigue damage interaction factor. While conceptually elegant, this approach has some pragmatic difficulties in addition to the theoretical concerns identified above. The first concerns the evaluation of test data. While strain range and number of cycles to failure are direct measurements, creep damage is a calculated parameter sensitive to modeling assumptions which tend to be swept into the damage interaction factor. The second concern is perhaps the greater issue from the standpoint of complexity. In addition to the complications noted above in determination of strain based on elastic analysis, there is another layer of complexity in the bounding of elastically determined stress levels to compute creep damage. 


\section{Simplified Criteria}

\subsection{Basic Strategy}

In the above background discussion, several factors were identified which make the design criteria of $\mathrm{NH}$ difficult to apply in the conceptual and early preliminary stages of design. Although the use of solid element FEA is now relatively commonplace, the results of these analyses require a complex process of categorization in order to assess their acceptability. Therefore, a primary strategy of the simplified criteria is to eliminate or at least minimize stress classification, particularly in the area of structural discontinuities where the process is most difficult. A key part of this strategy is the use of the so called "design-by-rule" procedures to determine required wall thicknesses. These procedures are already permitted by $\mathrm{NH}$.

Another area of uncertainty and complexity is the NH procedures for evaluation of creepfatigue damage. As noted above, there are questions regarding accuracy of the linear damage accumulation rule, particularly at very high temperatures. These concerns are exacerbated by the complexities of the elastic analysis rules which must be used pending the availability of procedures and material models for inelastic analysis. For this area, the strategy is to revert to the elastic analysis creep-fatigue methodology used in earlier high temperature code cases where the effect of hold time on creep-fatigue life was included directly in the design curve. The main reason this approach was replaced in later versions was the concern and conservatism associated with accounting for elastic follow-up effects. However, in recent years there has been more insight developed in how to deal with those issues.

The next area to be addressed is strain limits. In the current NB and NH procedures, evaluation of primary-plus-secondary stresses/strain limits is done after the primary stress/wall sizing evaluation and before the cycle life assessment. This fits quite logically with the interaction analysis sequence. In this simplified procedure, evaluation of strain limits is delayed until the basic issues of wall sizing and cycle life are resolved. The high temperature rules are restructured to more closely resemble the rules of Subsection NB and separation of primary and secondary stresses are avoided.

\subsection{Allowable Stresses and Loading Categories}

The general procedures in NH apply to the definition of loading conditions (NH-3113) and the selection of Design (NH-3222) and Service limits (NH-3223, -3224 and -3225). In addition, since wall thickness is determined by design-by-rule procedures, the thickness determination for the various loading categories is based on the primary membrane stress intensity limit for that loading category. Thus for Level A and B Service Loadings (NH-3223) the appropriate allowable stress for use in design-by-rule procedures is $S_{m t}$ as defined in NH-3221(b) and shown in Appendix B of this document. 


\subsection{Load Controlled Limits}

Numerous sections of the ASME Code have rules for determining thickness requirements for various vessel components including reinforcement requirements for openings. In Sections I, Section VIII Div 1, and Section III Subsections NC and ND, among others, the design-by-rule provisions are mandatory. Although Section III Subsection NB and Section VIII Divison 2 provide design-by-analysis rules, they also allow for determination of thickness requirements based on design-by-rule. In NB these rules are in NB-3300, $-3400-3500$ and -3600 for vessels, pumps, valves and piping respectively. With modification of the applicable allowable stress, $\mathrm{NH}$ also currently permits the use of the design-by-rule provisions of Subsection NB in some circumstances for determination of primary stresses and wall thicknesses. In these simplified criteria, wall thickness requirements are based on the design-by-rule approach, thus avoiding the need to deconstruct FEA results into primary stresses from the primary-plus-secondary-plus peak stress output.

A remaining issue for elevated temperature is the reduction in life due to different loads for different times; for example, a short time load at higher temperatures than normal operating conditions. This issue is handled in NH by a time fraction evaluation based on the allowable time duration at the primary stress levels for that particular loading condition. Since this reverts back to load classification, a different, more approximate approach is taken using the simplified criteria. In this approach, the required thickness is computed for each loading condition using the allowable primary membrane stress(s) for the corresponding Service Loading. The final thickness requirement can be approximated by the expression:

$$
\begin{aligned}
& \mathrm{t}_{\mathrm{r}}=\mathrm{t}_{1}\left(1+\mathrm{t}_{2} / \mathrm{t}_{1}+\mathrm{t}_{3} / \mathrm{t}_{1}+\ldots \mathrm{t}_{\mathrm{n}} / \mathrm{t}_{1}\right)^{1 / 5} \\
& \text { where } t_{r}=\text { required thickness for combined loading conditions, } \\
& t_{1}=\text { largest required thickness for a given loading, and } \\
& t_{1}>t_{2}>t_{3}>\ldots . . t_{n} \text {. }
\end{aligned}
$$

For example, for two loading conditions where $\mathrm{t}_{1} \approx \mathrm{t}_{2}, \mathrm{t}_{\mathrm{r}} \approx 1.15 \mathrm{t}_{1}$. For three loading conditions where $\mathrm{t}_{2} \approx \mathrm{t}_{3} \approx 2 / 3 \mathrm{t}_{1}, \mathrm{t}_{\mathrm{r}} \approx 1.20 \mathrm{t}_{1}$. Since $\mathrm{t}_{\mathrm{r}}$ will never be less than 1.0 , for most cases the range of the required thickness for combined loading conditions will be from 1.0 times the largest single required thickness to about a $20 \%$ increase to account for additional loading conditions.

\subsubsection{Reinforcement of Openings and Nozzle Loads}

Although all of the design-by-rule procedures cover reinforcement of openings, they do not address nozzle loads from connected piping nor do they address thermal stresses. Ordinarily, these additional loadings would be addressed through an FEA with the attendant requirements for load classification. However, this runs counter to the stated goal of avoiding load classification, particularly the separation of primary and secondary stresses. There are several strategies which may be considered for this problem. 


\subsubsection{Delay definition of nozzle loads}

The first strategy is, interestingly, to ignore it. If it is a relatively small nozzle compared to the vessel, for example one that meets the geometric limitations in Table NB-3339.3-1 for nozzles which do not require reinforcement, then the primary loading transmitted to the vessel will probably not significantly impact the vessel wall stresses. Even if there is a potential for significant nozzle loadings one could take the viewpoint that this constitutes a to-be-determined design constraint on the piping system. Clearly this approach has pitfalls, and is discouraged from being used, but that doesn't prevent its common use.

\subsubsection{Evaluate nozzle loads using piping stress indices}

The second strategy is to take advantage of the stress indices provided for piping components but change the allowable stress to be consistent with vessel stress classification. NB-3683.8 "Branch Connections per NB-3643" provides stress indices for branch connections which are similar to the nozzles described in NB-3339. More specifically, NB-3683.3(c) provides primary plus secondary stress indices for branch connections with similar configuration and geometric constraints as the nozzles of NB3339. The guidance provided in NB and NH for classification of stresses resulting from applied loadings is, frankly, confusing and difficult to interpret. Guidance depends upon the source of loading and the location in the vessel, nozzle and connecting piping. The situation is further exacerbated by the $\mathrm{NH}$ requirement that, generally, pressure induced discontinuity stresses are considered non-relaxing and classified as primary when satisfying deformation controlled limits. Based on the above and for this part of the simplified criteria, the following check may be used to assess the impact of nozzle loading:

$C_{1}\left(P D_{o} / 2 T_{r}\right)+C_{2 b}\left(M_{b} / Z_{b}\right)+C_{2 r}\left(M_{r} / Z_{r}\right) \leq$ lower of $1.5 S_{m}$ or $1.25 S_{t}$ with nomenclature defined in NB-3600 with the following exceptions:

a. "run" corresponds to the vessel and "branch" corresponds to the nozzle,

b. $S_{m}$ and $S_{t}$ are as defined in NH-3221(b) and shown in Appendix B of this document,

c. the moment, $M$, includes restrained thermal expansion loading. (The appropriate value for restrained thermal expansion requires additional consideration as described later)

In the above equation, the term $1.5 S_{m}$ is based on the allowable primary membrane plus bending stress for piping as given in NB-3652 for temperatures below the creep regime. In the creep regime, the equivalent allowable stress is given by $1.25 S_{t}$ as described in NH-3223(c) and (d).

\subsubsection{Use FEA results to evaluate nozzle loads}

The third strategy is based on linearization of elastic FEA results similar to the strain limit check discussed below. For this evaluation the FEA model should include internal 
pressure (and external if applicable), sustained mechanical loads and restrained thermal expansion, which requires additional discussion as previously indicated. The results should be linearized to obtain a uniform membrane stress across the wall thickness. This stress should satisfy the limits of the allowable primary membrane stress(s) for the corresponding Service Loading.

\subsubsection{Determination of nozzle loads}

As noted in the preceding discussion, determination of the appropriate loading condition for restrained thermal expansion requires further explanation. The problem is that a nozzle loading based on an elastically calculated piping analysis will result in unrealistically high nozzle loads. Even if the inelastic response of the piping is considered, if the piping yields as a whole as opposed to only yielding at local discontinuities when the system cools down, then the nozzle load due to restrained thermal expansion will be cycled severely at each shutdown loading cycle. Therefore, a piping design object in this temperature range is to achieve a well balanced configuration in which the restrained thermal expansion loading monotonically decays over time. This can be achieved by following the allowable stress criteria defined below under the strain limits section of deformation controlled limits (3.4.2.). Since a final piping configuration is probably not available in the early stages of design, a normal practice is to establish a mutually compatible set of load limits for the piping and the vessel nozzles such that the load that the piping can exert is limited to less than the nozzle design load for the vessel. The actual loadings will vary with time; however, the authors suggest that these preliminary loading sets be based on allowable stress levels for the full design life and the preliminary design assessment be similarly based. This approach is viable only if the piping is designed for monotonic relaxation of the restrained thermal expansion stresses as described above in 2.2.2.1.

\subsection{Deformation Controlled Limits}

\subsubsection{Creep-Fatigue Evaluation}

As previously described, the strategy for creep-fatigue in these simplified criteria is to revert to the elastic analysis creep-fatigue methodology used in earlier high temperature code cases where the effect of hold time on creep-fatigue life was included directly in the design curve. There is also the question as to how to compute the appropriate strain range to use in conjunction with the design curves. There are two basic approaches that can be used with these criteria. The first is based strictly on the results of elastic FEA and the other is based on the use of isochronous stress-strain curves in an inelastic FEA. In both cases the maximum value of the strain is relevant, eliminating the need to deconstruct the stress/strain results into load classifications for this evaluation.

\subsubsection{Strain Range Determination}

In the context of these simplified criteria there are two ways in which the results of elastic FEA may be used to assess creep-fatigue damage. In one approach, results of elastic FEA 
can be used directly to determine the applicable strain range if they are adjusted to account for potential strain redistribution. The second approach is to capture the effects of strain redistribution in the test specimen.

\subsection{Use of elastic FEA results for strain range}

For these criteria, the first approach, adjustment of elastic FEA results, is based on one of the options in $\mathrm{NH}$ for evaluation of creep-fatigue damage using elastic analysis.

Appendix $\mathrm{T}$ in $\mathrm{NH}$ provides three expressions for determining strain range. The simplest and most conservative approach is given in T-1432(e). In accordance with T-1432 these results are then adjusted upward to account for multiaxiality and Poisson's effects.

Corum (5) has proposed using a simple factor of 1.6 to bound these effects. On the other hand, Shimakawa, et al (6) have found that the Neuber relationship upon which T-1432 is based is conservative by a factor of 1.6 by analyzing representative geometries and loading conditions. Similar results are discussed by Marriott (7). However, there are further considerations. The procedures of T-1432 are based on classification of some stresses at elevated temperature as primary which are usually considered secondary; a procedure which is probably somewhat conservative. On the other hand, T-1432 is also based on the assumption that follow-up is negligible for thermal stresses, which is unconservative as shown by Simakawa's results that were solely based on thermal stresses. However, in some of those cases the strain redistribution was probably over predicted for the stress regimes and configuration addressed by these criteria. Obviously there is a lot more work that could be done in this area.

Given the small amount of additional effort required for inelastic FEA, further investigation and development of simplified elastic FEA methods is likely unwarranted. Hence, for elastic FEA criteria, the basic formula from T-1432(e) will be used without any additional factors. The relationship for estimating the strain range for the creepfatigue analysis thus becomes:

$$
\begin{array}{rlrl}
\Delta \epsilon & =\left(K \Delta \epsilon_{\text {max }}\right) & & \text { for }\left(K \Delta \epsilon_{\text {max }}\right) \leq 3 \hat{S}_{m} / E \\
& =\left(K / 3 \hat{S}_{m} / E\right)\left(K \Delta \epsilon_{\text {max }}\right) & \text { for }\left(K \Delta \epsilon_{\text {max }}\right)>3 \hat{S}_{m} / E
\end{array}
$$

Note that the term $\left(K \Delta \epsilon_{\text {max }}\right)$ is the total strain as calculated from the elastic FEA., $\hat{S}_{m}$ is as defined in T-1324(c) except that $S_{t}$ is substituted for $S_{r}$, and $K$ is the theoretical elastic stress concentration factor.

\subsection{Use of elastic FEA with follow-up test data}

The other way to use the elastic FEA results directly is to account for the strain redistribution in the creep-fatigue design curves. Reference (14) provides a methodology for doing this by using the results of hold time creep-fatigue tests using test specimens with built-in elastic follow-up. This method may be utilized if and when the appropriate test data have been developed. 


\subsection{Use of inelastic FEA results for strain range}

A somewhat more accurate and potentially less conservative method to determine the strain range is to use an inelastic FEA based on isochronous stress/strain curves. The isochronous curves are provided for a family of constant times at stress. For these criteria, a reference cycle time of $1000 \mathrm{hr}$ is suggested, which means that the inelastic FEA is based on the $1000 \mathrm{hr}$ isochronous stress/strain curve.

\subsection{Combining cycles}

Methods are provided in NH, T-1413 and -1414 to determine the equivalent strain range. For the purpose of these criteria for very high temperatures, the greatest strain range(s) is assumed to occur on a periodic shutdown cycle. Under those circumstances, for expediency in the early stage of design, one acceptable approach is to look at the maximum value of effective strain to estimate the range for the cycle. Cycles in the same general direction may be counted separately and those in the opposite direction may be combined numerically, recognizing that this is a shortcut suitable for the conceptual/preliminary phase of design only.

\subsubsection{Creep-Fatigue Design Curve}

\subsection{Creep-fatigue data sources}

A limited number of references were located with strain controlled creep-fatigue data on Alloy 617 in the temperature range of $950-1000^{\circ} \mathrm{C}$. In Ref (6), Figure 3.20 (Kitagawa et. al. 1979) shows data at two strain ranges (1.3 and $2.2 \%$ ) and two cycle types (tension compression and tension only holds) for hold times in helium ranging from a few seconds to about 60 minutes. There are German references, (9) and (10), which report segments of the data which are more fully reported in (11) and (12). The most useful information was found in (12) for a strain range of $0.6 \%$ at $950^{\circ} \mathrm{C}$ in He with hold times to $120 \mathrm{~min}$ and four cycle types. Reference (11) provided information on hold time effects at 1.5\%, $0.6 \%$ and $0.3 \%$ strain ranges based on based on the ratio of cycles to failure with hold time to cycles to failure without but did not provided continuous cycling fatigue life data without hold time. Yukawa's(15) work provided information on continuous cycling fatigue life which was in good agreement with He data from (12). Interestingly, the Kitagawa data showed the tension-compression cycle to be about the same or somewhat more damaging than the tension only cycle whereas the German data showed the tension only cycle to be significantly more damaging than the tension compression cycle. The Germans also conclude that fatigue resistance in helium is superior to that in air. None of the reported data showed a saturation effect with hold time; but, Meurer (17) referenced unpublished data on 617 at $950^{\circ} \mathrm{C}$ to make the point that "...this will probably not be a critical design limitation". If there were no saturation effect, then, for the long hold times associated with actual operation, the allowable number a cycles and/or allowable strain range would 
decrease to levels which would provide a minimal, if any, design envelope. That would, indeed, be a "...critical design limitation". This indicates the need to develop the required data bases for the structural materials to be used.

\subsection{Development of design curve in $\mathrm{He}$}

The first step in the process to derive a creep-fatigue design curve in helium (He) was to construct a continuous cycling curve anchored by the data in (12) and in general agreement with the General Electric (GE) He data reported in Yukawa's (15) work. The cyclic life reduction factors with some extrapolation (to about 3-5hr) were then used to generate a hold time creep-fatigue curve. Engineering judgment was used in the extrapolation to avoid incongruities such as a longer life at higher strain ranges. Factors of two and twenty, on strain and cycles respectively, were then applied and the cusp smoothed out to provide a continuous curve.

\subsection{Development of design curve in air}

The creep-fatigue design curve in air was developed from Yukawa's (16) continuous cycling design curve in air by de-rating the allowable number of cycles using the same cyclic life reduction factors as were used on the He fatigue data.

\subsubsection{Strain Limits}

$\mathrm{NH}$ provides two basic routes to satisfaction of strain limits. The first route is through a full inelastic analysis with limitations on accumulated membrane, membrane-plusbending and membrane-plus-bending-plus-peak strain. Implementation of this approach requires mathematical representations of material behavior which are not currently available and are beyond the scope of this simplified criteria. The use of the reference stress approach, which is currently used in the British Standard R5, will likely be investigated in the future for inclusion into $\mathrm{NH}$, but is beyond the scope of this report.

The second route to satisfaction of strain limits is through elastic and so-called simplified inelastic analysis in which the primary and secondary stresses are incorporated in limits based on ratcheting models and the creep characteristics of an elastic core. As discussed earlier, implementation of these procedures requires parsing and factoring the FEA results into appropriate stress classifications. Avoiding this complexity is a main goal of this simplified procedure. Unfortunately, there is not a completely satisfactory way around the problem; one reason for leaving this issue for analysis after the other criteria have been satisfied. Although the parsing of FEA results can not be eliminated, it can be greatly simplified by considering a modified shakedown model rather than the above described ratcheting model. Such a model is already incorporated in the rules in Appendix T of NH, paragraph T-1431(a)(2). Hence, this existing model is the recommended criteria for these simplified rules except that $S_{t}$ is substituted for $S_{r}$. 
The rule is thus:

$\left(P_{L}+P_{b}+Q\right)_{R A N G E} \leq 3 \hat{S}_{m}$

where $\hat{S}_{m}$ is as defined in T-1324(c) except that $S_{t}$ is substituted for $S_{r}$ as described in 2.2.2.1

And the value of $\left(P_{L}+P_{b}+Q\right)$ is obtained by linearizing the elastic FEA results to eliminated peak stresses, $F$, where $F$ is discussed in Figure NB-3222-1 of Subsection NB. Note that some peak thermal stresses such as local hot spots will not be eliminated but that conservatism is warranted by the resultant simplicity and the relatively few such occurrences. Note also that the above criteria will also be satisfied if the total stress range $\left(P_{L}+P_{b}+Q+F\right)_{R A N G E}$ is compared to $3 \hat{S}_{m}$ thus avoiding the linearization process altogether.

\subsection{Buckling and Instability}

$\mathrm{NH}$ provides rules for evaluating buckling and instability in two categories based on load duration. The time independent rules are for the regime in which creep effects are not significant and the time dependent rules are for conditions when creep effects must be considered. For Alloy 617 at very high temperatures, all but dynamic loads such as those due to seismic inputs and pneumatic pressure pulses should be considered time dependent.

For the purposes of these criteria, such dynamic events are evaluated using inelastic FEA with time-independent buckling factors provided in Table T-1521-1 of NH and with the hot tensile curve from the isochronous stress-strain curve approximated by an elasticperfectly-plastic curve. For all other loading conditions, buckling and instability should be evaluated using the time dependent load controlled buckling factors in Table T-1522-1 in an inelastic FEA based on the isochronous stress-strain curve appropriated for the load duration. Note that the buckling factors are based on expected minimum stress strain behavior so the average isochronous stress-strain curves need to be adjusted downward in accordance with the procedure of T-1510 $(\mathrm{g})$. Also, since currently available isochronous stress-strain curves for Ally 617 do not extend beyond 100,000hr, the 100,000 hr curves should be further reduced by multiplying by a factor of 0.67 for load durations of 525,600 hrs. For intermediate load durations, linear interpolation should be used.

\subsection{Additional Considerations}

\subsubsection{Configuration Constraints}

\subsubsection{Nozzles}

Only full penetration welded nozzles with integral reinforcement as described in NB3337.2 and NB-3339.1 may be used. 


\subsubsection{Stress Concentrations}

In Reference (14) the impact of stress concentrations was discussed with regard to insuring that the localized peak stresses would relax in areas of global discontinuity such as a shell to head joint. The following expression was developed to insure peak stress relaxation:

$\mathrm{K} \leq \mathrm{q}_{\mathrm{n}} /\left(\mathrm{q}_{\mathrm{n}}-1\right)$, where $\mathrm{q}_{\mathrm{n}}$ is the global follow-up

and can generally be represented by a value of $\mathrm{q}_{\mathrm{n}}=2$ This results in a recommended upper limit on stress concentrations of $\mathrm{K}=2.0$ for application of these criteria.

\subsubsection{Welds}

$\mathrm{NH}$ provides weld strength reduction factors, reduced strain limits and requirements for determination of the stress at welds. For these criteria the following recommendations are made:

(a) The allowable primary membrane stress at welds be reduced by a factor of 0.67 ,

(b) the allowable strain range on the creep-fatigue design curve also be reduced by a factor of 0.67 , and

(c) the stress concentration of the weld geometry be held $\leq 1.5$.

\section{Summary}

Suggested simplified design criteria for very high temperature Generation IV components and materials have been provided. While the accompanying material in the Appendices addresses only Alloy 617, the design criteria should be applicable for other materials as well, but only for the same intended purpose - rapid feasibility assessments of the structural viability of very high temperature components in conceptual and early preliminary design phases for Generation IV reactors. More detailed plans for high temperature design methods are provided in (4). These include development or modification of unified constitutive equations, isochronous curves, creep-fatigue failure criteria, procedures for addressing weldments and notches, improvements in simplified methods for final design, and simple structural tests to validate models and methods. These developments will focus initially on two main candidate materials for very high temperature applications: Alloy 617 and $9 \mathrm{Cr}-1 \mathrm{Mo}$. Additional materials will be addressed as the programs develop and materials for each component are down-selected. 


\section{References}

(1) 2001 ASME BOILER \& PRESSURE VESSEL CODE, Section III Division 1 Subsection NH "Class 1 Components in Elevated Temperature Service"

(2) 2001 ASME BOILER \& PRESSURE VESSEL CODE Section III, Division 1 Subsection NB "Class 1 Components"

(3) "Guidelines on Processing Elastic Finite Element Analysis Results for Assessment of ASME Code Stress Limits" Prepared by Subgroup on Design Analysis. Rev. 18

(4) J.M. Corum, T.E.McGreevy, " R\&D Plan for Development of High-Temperature Structural Design Technology for Generation IV Reactor Systems", ORNL Draft Letter Report, September 15, 2004.

(5) Corum, J. M., "Appendix 5 - Mandatory Design Based on Creep-Fatigue and Creep Damage" Attachment 2 to Minutes of ASME B\&PV CODE Subgroup on Elevated Temperature Design, May, 1994

(6) Shimikawa, T., "Sophisticated Creep-Fatigue Life Estimation Scheme far Pressure Vessel Components Based on Stress Redistribution Locus Concept" PVP-Vol. 472, Elevated Temperature Design and Analysis, Nonlinear Analysis, and Plastic Components - 2004 July 25-29, 2004, PVP2004-2258

(7) Marriott, D. L., "Origins of Relaxation Method and Its Applications" Presented at Joint JPVRC/PVRC ETD Committee Meeting, Houston, Texas, October 22, 2002

(8) "Material Behavior in HTGR Environments" Argonne National Laboratory, NUREG/CR-6824, ANL-02/37

(9) Lehmann, H. J., Becker, M., Ludeke, M. "Development and Validation of an Improved Creep-Fatigue Interaction Rule for Lifetime Determination of High Temperature Components"

(10) Breitling, H., Dietz, W., Penkalla, H. J., "Evaluation of Mechanical Properties of the Alloy NiCr22Co12Mo (Alloy 617) for Heat Exchanging Components of HTGRs"

(11) Meuher, H. P., Brietling, H., Dietz, W., "Influence of Hold Time and Strain Rate on the LCF-Behavior of Alloy 617 at 950C" Proc. 2nd Int. Conf. "Low Cycle Fatigue and Elasto-Plastic Behavior of Materials", Munich ed. K. T. Rie (1987) 
(12) Rao, K. B. S., Meuer, H. P., Schuster, H. "Creep-Fatigue Interaction of Alloy 617 at 950C in Simulated Nuclear Reactor Helium" Materials Science and Engineering A 104 (1988) pp37-51

(13) Nickel, H., Schubert, F., Breitling, H., Bodmann, E. "Development and Qualification of Materials for Structural Components for the High-Temperature Gas-Cooled Reactor" Nuclear Engineering and Design 121 (1990) 183-192, NorthHolland

(14) Jetter, R. I. "An Alternate Approach to Evaluation of Creep-Fatigue Damage for High Temperature Structural Design Criteria" PVP-Vol. 5 Fatigue, Fracture, and High Temperature Design Methods in Pressure Vessels and Piping, Book No. Ho1146-1998

(15) Yukawa, S. "Re-analysis of Inconel 617 fatigue data" Committee Correspondence, Sept. 15, 1988

(16) Yukawa, S. "Elevated Temperature Fatigue Design Curves for Ni-Cr-Co-Mo Alloy 617" JSME/ASME Joint International Conf. on Nuclear Eng., Nov. 4-7, 1991

(17) Meuer, H. et al "Investigations on the Fatigue Behavior of High-Temperature Alloys for High-Temperature Gas-Cooled Reactor Components" Nuclear Technology, Vol. 66, Aug. 1984 


\section{Appendices}
A. Simplified Criteria Summary
B. Allowable Stress Values
C. Creep-Fatigue Design Curves
D. Isochronous Stress/Strain Curves 


\section{Appendix A - Simplified Criteria Summary}

For more information on the rationale for these criteria, the user is referred to the main text of this document. Numbers shown in parentheses after the titles below are the applicable sections of the main text.

\section{A.1. Load Controlled Limits (3.3.)}

The required wall thickness shall be determined using the sizing provisions in Subsection NB in NB-3300, $-3400-3500$ and -3600 for vessels, pumps, valves and piping respectively. The required thickness is computed for each loading condition using the allowable primary membrane stress(s) for the corresponding Service Loading. The final thickness requirement can be approximated by the expression:

$$
\mathrm{t}_{\mathrm{r}}=\mathrm{t}_{1}\left(1+\mathrm{t}_{2} / \mathrm{t}_{1}+\mathrm{t}_{3} / \mathrm{t}_{1}+\ldots \mathrm{t}_{\mathrm{n}} / \mathrm{t}_{1}\right)^{1 / 5}
$$

where $t_{r}=$ required thickness for combined loading conditions

$\mathrm{t}_{1}=$ largest required thickness for a given loading, and

$$
\mathrm{t}_{1}>\mathrm{t}_{2}>\mathrm{t}_{3}>\ldots . . \mathrm{t}_{\mathrm{n}}
$$

For example, for two loading conditions where $\mathrm{t}_{1} \approx \mathrm{t}_{2}, \mathrm{t}_{\mathrm{r}} \approx 1.15 \mathrm{t}_{1}$. For three loading conditions where $\mathrm{t}_{2} \approx \mathrm{t}_{3} \approx 2 / 3 \mathrm{t}_{1}, \mathrm{t}_{\mathrm{r}} \approx 1.20 \mathrm{t}_{1}$. Since $\mathrm{t}_{\mathrm{r}}$ will never be less than 1.0 , for most cases the range of the required thickness for combined loading conditions will be from 1.0 times the largest single required thickness to about a $20 \%$ increase to account for additional loading conditions.

\section{A. 1.1. Nozzle Loads (3.3.1.)}

There are three options for consideration of nozzle loads:

(a) Defer evaluation to later with the consideration that this constitutes a to-bedetermined design constraint on the piping system. For relatively small nozzles meeting the geometric limitations in Table NB-3339.3-1 for nozzles which do not require reinforcement, then the primary loading transmitted to the vessel will probably not significantly impact the vessel wall stresses.

(b) Evaluate the nozzle loads using piping stress indices in accordance with the following procedure:

$$
\left(P D_{o} / 2 T_{r}\right)+C_{2 b}\left(M_{b} / Z_{b}\right)+C_{2 r}\left(M_{r} / Z_{r}\right) \leq \text { lower of } 1.5 S_{m} \text { or } 1.25 S_{t}
$$

nomenclature defined in NB-3600 with the following exceptions:

(1) "run" corresponds to the vessel and "branch" corresponds to the nozzle,

(2) $S_{m}$ and $S_{t}$ are as defined in NH-3221(b) and shown in Appendix B of this document,

(3) the moment, $M$, includes restrained thermal expansion loading. 


\section{Appendix A - Simplified Criteria Summary (continued)}

(c) Use FEA results to evaluate nozzle loads due to internal pressure, sustained mechanical loads and restrained thermal expansion. The results should be linearized to obtain a uniform membrane stress across the wall thickness. This stress should be compared to the allowable primary membrane stress(s) for the corresponding Service Loading.

See also the discussion in 3.3.1.4." Determination of nozzle loads"

\section{A.2. Deformation Controlled Limits}

\section{A.2.1 Creep-Fatigue Evaluation (3.4.1.)}

Determine the strain range for each cycle from the following expression:

$$
\begin{array}{rlrl}
\Delta \epsilon & =\left(K \Delta \epsilon_{\max }\right) & & \text { for }\left(K \Delta \epsilon_{\max }\right) \leq 3 \hat{S}_{m} / E \\
& =\left(K / 3 \hat{S}_{m} / E\right)\left(K \Delta \epsilon_{\text {max }}\right) & \text { for }\left(K \Delta \epsilon_{\text {max }}\right)>3 \hat{S}_{m} / E
\end{array}
$$

Note that the term $\left(K \Delta \epsilon_{\max }\right)$ is the total strain as calculated from the elastic FEA., $\hat{S}_{m}$ is as defined in T-1324(c) except that $S_{t}$ is substituted for $S_{r}$, and $K$ is the theoretical elastic stress concentration factor. Strains for different cycles may be combined as discussed in 3.4.1.1.4 "Combining cycles".

An alternative method is to determine the strain range using an inelastic FEA based on isochronous stress/strain curves. For these criteria, it is suggested that a reference cycle time of $1000 \mathrm{hr}$ be used which means that the inelastic FEA is based on the $1000 \mathrm{hr}$ isochronous stress/strain curve.

The resulting strain ranges are then evaluated using the Design Creep-Fatigue Curves for the appropriate atmosphere, He or air, as shown in Appendix C. A linear damage summation is used to combine the damage due to different cycles.

\section{A.2.2. Strain Limits (3.4.2.)}

Strain limits are satisfied if the following condition is met.:

$$
\left(P_{L}+P_{b}+Q\right)_{R A N G E} \leq 3 \hat{S}_{m}
$$

where $\hat{S}_{m}$ is as defined in T-1324(c) except that $S_{t}$ is substituted for $S_{r}$.

And the value of $\left(P_{L}+P_{b}+Q\right)$ is obtained by linearizing the elastic FEA results to eliminated peak stresses, $F$, where $F$ is discussed in Figure NB-3222-1 of Subsection NB. Note that the above criteria will also be satisfied if the total stress range $\left(P_{L}+P_{b}+Q+\right.$ $F)_{R A N G E}$ is compared to $3 \hat{S}_{m}$ thus avoiding the linearization process altogether. 


\section{Appendix A - Simplified Criteria Summary (continued)}

\section{A.3. Buckling and Instability (3.5.)}

Dynamic events are evaluated using inelastic FEA with time-independent buckling factors provided in Table T-1521-1 of Subsection NH and with the hot tensile curve from the isochronous stress-strain curve approximated by an elastic-perfectly-plastic curve. For all other loading conditions, buckling and instability should be evaluated using the time dependent load controlled buckling factors in Table T-1522-1 in an inelastic FEA based on the isochronous stress-strain curve appropriated for the load duration. Note that the buckling factors are based on expected minimum stress strain behavior so the average isochronous stress-strain curves need to be adjusted downward in accordance with the procedure of $\mathrm{T}-1510(\mathrm{~g})$. Also, since currently available isochronous stress-strain curves for Ally 617 do not extend beyond 100,000hr, the curves should be further reduced by multiplying by a factor of 0.67 for longer load durations.

\section{A.4. Additional Considerations}

\section{A.4.1. Configuration Constraints}

\section{A.4.1.1. Nozzles (3.6.1.1.)}

Only full penetration welded nozzles with integral reinforcement as described in NB3337.2 and NB-3339.1 may be used.

\section{A.4.1.2. Stress Concentrations (3.6.1.2.)}

The recommended upper limit on stress concentrations is $\mathrm{K}=2.0$ for application of these criteria.

\section{A.4.2. Welds (3.6.2.)}

For these criteria it is recommended that:

(a) The allowable primary membrane stress at welds be reduced by a factor of 0.67

(b) The allowable strain range on the creep-fatigue design curve also be reduced by a factor of 0.67 , and

(c) The stress concentration of the weld geometry be held $\leq 1.5$. 


\section{Appendix B - Allowable Stress Values}

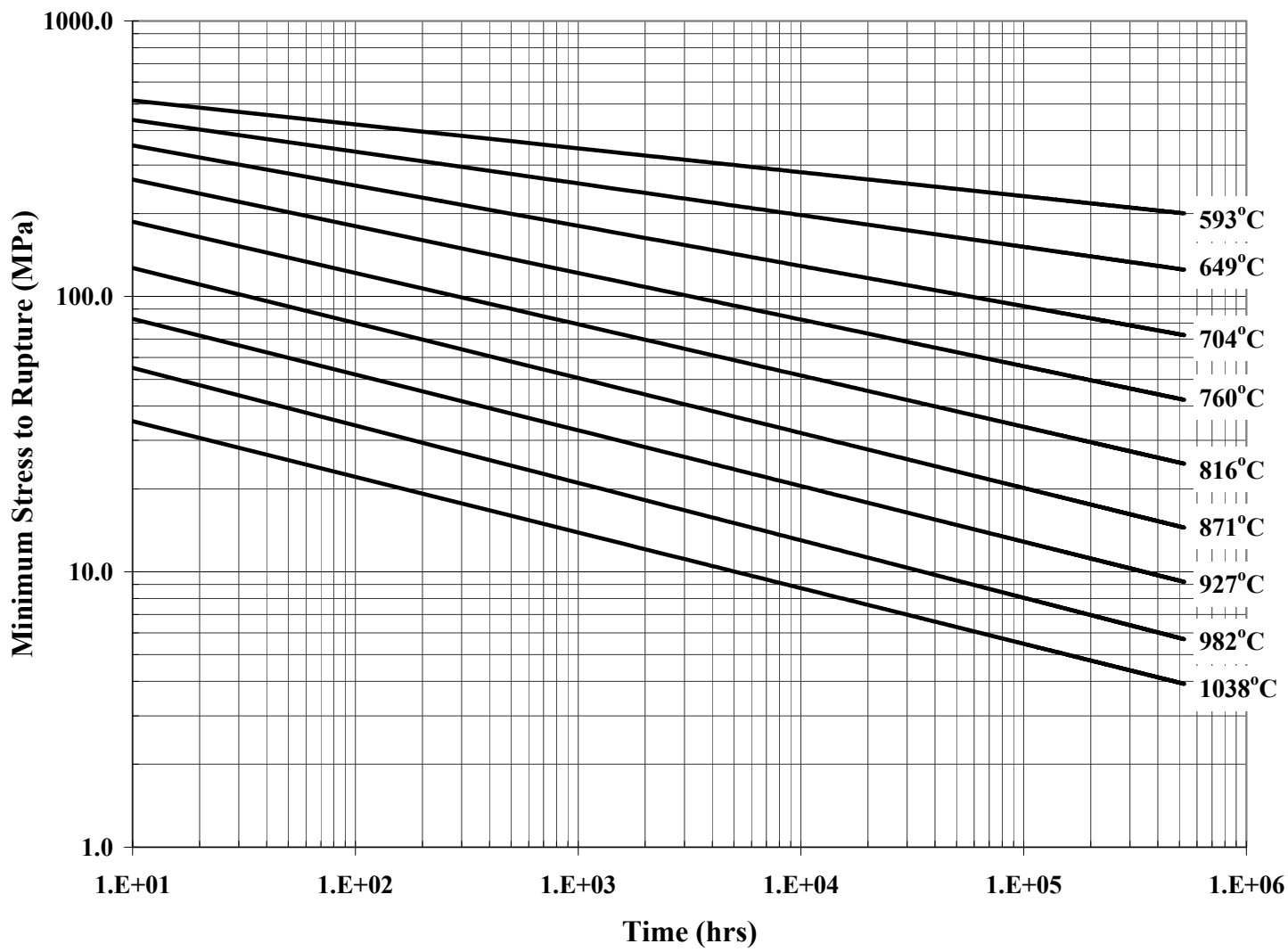

Figure B-1 Stress Rupture Curves for Alloy 617 
Appendix B - Allowable Stress Values (continued)

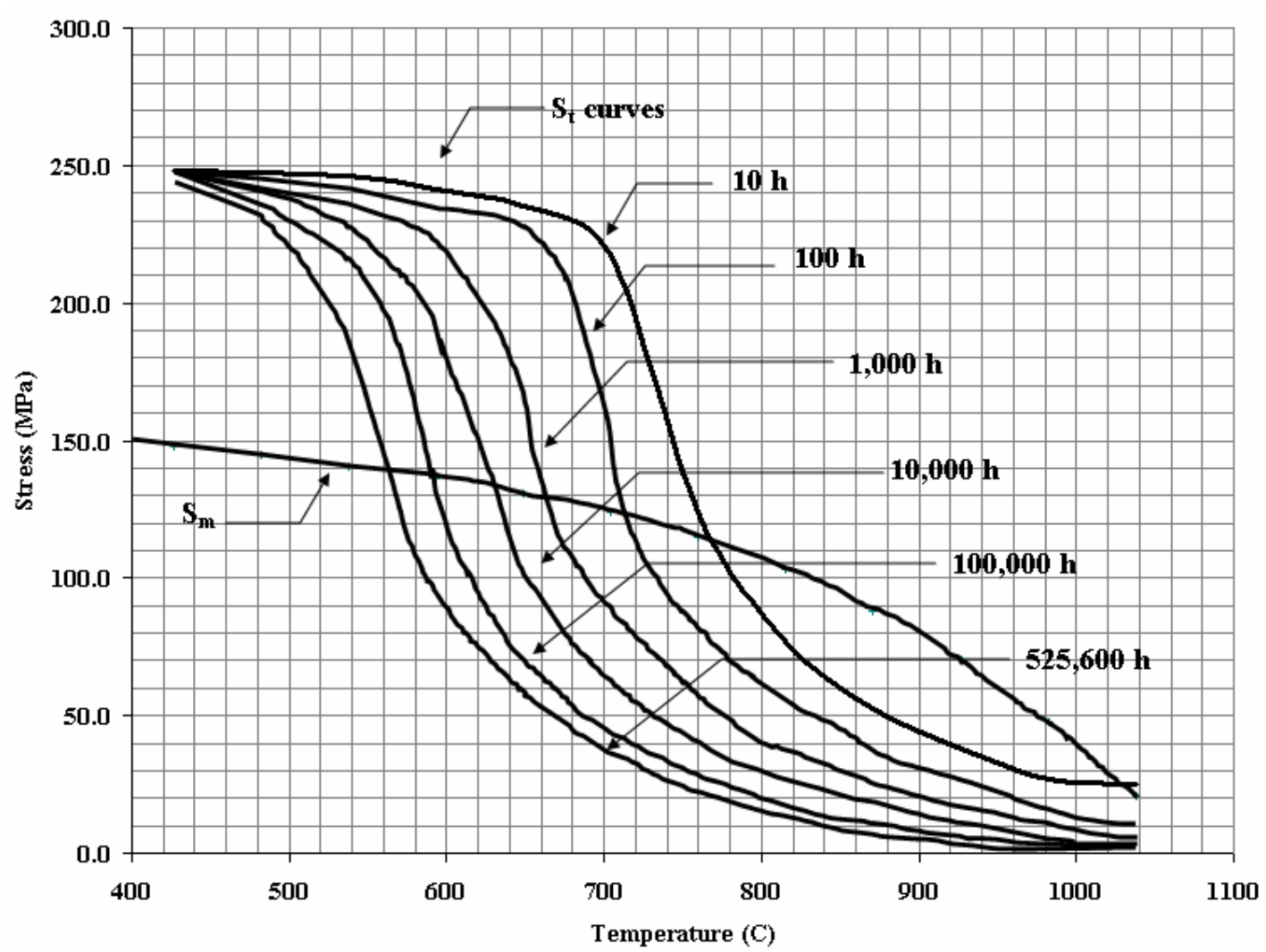

Figure B-2 Allowable Stress Levels for Alloy 617 


\section{Appendix B - Allowable Stress Values (continued)}

The values listed in the tables are provided to assist in interpolation of allowable stress values and should not be interpreted to indicate that allowable stress values are accurate to $0.1 \mathrm{MPa}$ or similar.

Table B-1 Allowable Stresses for Alloy 617 (SI units)

\begin{tabular}{|c|c|c|c|c|c|}
\hline $\operatorname{Temp}(\mathrm{C})$ & $\overline{S_{m}}$ & Time (h) & $S_{r} \min$ & $\overline{S_{t}}$ & $\mathbf{S}_{\mathrm{mt}}$ \\
\hline \multirow[t]{6}{*}{704} & 124.0 & 10 & 325.9 & 217.7 & 124.0 \\
\hline & & 100 & 260.4 & 137.8 & 124.0 \\
\hline & & 1000 & 195.7 & 89.6 & 89.6 \\
\hline & & 10000 & 136.4 & 64.8 & 64.8 \\
\hline & & 100000 & 86.1 & 45.5 & 45.5 \\
\hline & & 525600 & 71.0 & 36.5 & 36.5 \\
\hline \multirow[t]{6}{*}{760} & 115.1 & 10 & 250.8 & 124.0 & 115.1 \\
\hline & & 100 & 186.7 & 82.7 & 82.7 \\
\hline & & 1000 & 128.8 & 57.9 & 57.9 \\
\hline & & 10000 & 83.4 & 41.3 & 41.3 \\
\hline & & 100000 & 52.4 & 29.6 & 29.6 \\
\hline & & 525600 & 42.7 & 23.4 & 23.4 \\
\hline \multirow[t]{6}{*}{816} & 103.4 & 10 & 182.6 & 77.2 & 77.2 \\
\hline & & 100 & 125.4 & 56.5 & 56.5 \\
\hline & & 1000 & 81.3 & 38.6 & 38.6 \\
\hline & & 10000 & 51.0 & 27.6 & 27.6 \\
\hline & & 100000 & 31.0 & 19.3 & 19.3 \\
\hline & & 525600 & 26.2 & 14.5 & 14.5 \\
\hline \multirow[t]{6}{*}{871} & 88.2 & 10 & 126.1 & 52.4 & 52.4 \\
\hline & & 100 & 82.0 & 38.6 & 38.6 \\
\hline & & 1000 & 51.0 & 26.2 & 26.2 \\
\hline & & 10000 & 31.0 & 18.6 & 18.6 \\
\hline & & 100000 & 19.3 & 11.7 & 11.7 \\
\hline & & 525600 & 15.2 & 8.3 & 8.3 \\
\hline \multirow[t]{6}{*}{927} & 70.3 & 10 & 84.1 & 37.9 & 37.9 \\
\hline & & 100 & 52.4 & 26.2 & 26.2 \\
\hline & & 1000 & 32.4 & 17.9 & 17.9 \\
\hline & & 10000 & 20.0 & 12.4 & 12.4 \\
\hline & & 100000 & 12.4 & 6.9 & 6.9 \\
\hline & & 525600 & 9.6 & 4.1 & 4.1 \\
\hline \multirow[t]{6}{*}{982} & 47.5 & 10 & 56.5 & 26.9 & 26.9 \\
\hline & & 100 & 34.5 & 17.2 & 17.2 \\
\hline & & 1000 & 20.7 & 11.0 & 11.0 \\
\hline & & 10000 & 12.4 & 6.2 & 6.2 \\
\hline & & 100000 & 7.6 & 3.4 & 3.4 \\
\hline & & 525600 & 6.2 & 2.1 & 2.1 \\
\hline \multirow[t]{6}{*}{1038} & 20.7 & 10 & 37.2 & 24.8 & 20.7 \\
\hline & & 100 & 22.0 & 11.7 & 11.7 \\
\hline & & 1000 & 13.1 & 6.2 & 6.2 \\
\hline & & 10000 & 8.3 & 3.4 & 3.4 \\
\hline & & 100000 & 5.5 & 1.4 & 1.4 \\
\hline & & 525600 & 4.1 & 0.7 & 0.7 \\
\hline
\end{tabular}




\section{Appendix B - Allowable Stress Values (continued)}

Table B-2 Allowable Stresses for Alloy 617, continued (SI units)

\begin{tabular}{|c|c|c|c|c|c|}
\hline Temp (C) & $\mathbf{S}_{m}$ & Time (h) & $S_{r} \min$ & $\mathbf{S}_{t}$ & $S_{m t}$ \\
\hline \multirow[t]{6}{*}{427} & 148.1 & 10 & & 248.0 & 148.1 \\
\hline & & 100 & & 247.4 & 148.1 \\
\hline & & 1000 & & 247.4 & 148.1 \\
\hline & & 10000 & & 246.0 & 148.1 \\
\hline & & 100000 & & 245.3 & 148.1 \\
\hline & & 525600 & & 242.5 & 148.1 \\
\hline \multirow[t]{6}{*}{482} & 144.7 & 10 & & 247.4 & 144.7 \\
\hline & & 100 & & 246.0 & 144.7 \\
\hline & & 1000 & & 243.9 & 144.7 \\
\hline & & 10000 & & 241.2 & 144.7 \\
\hline & & 100000 & & 235.6 & 144.7 \\
\hline & & 525600 & & 230.8 & 144.7 \\
\hline \multirow[t]{6}{*}{538} & 140.6 & 10 & & 246.0 & 140.6 \\
\hline & & 100 & & 241.2 & 140.6 \\
\hline & & 1000 & & 236.3 & 140.6 \\
\hline & & 10000 & & 230.1 & 140.6 \\
\hline & & 100000 & & 216.3 & 216.3 \\
\hline & & 525600 & & 182.6 & 140.6 \\
\hline \multirow[t]{6}{*}{593} & 136.4 & 10 & 483.0 & 241.2 & 136.4 \\
\hline & & 100 & 425.8 & 234.3 & 136.4 \\
\hline & & 1000 & 364.5 & 222.5 & 136.4 \\
\hline & & 10000 & 299.7 & 186.0 & 136.4 \\
\hline & & 100000 & 234.3 & 124.0 & 124.0 \\
\hline & & 525600 & 186.0 & 95.1 & 95.1 \\
\hline \multirow[t]{6}{*}{649} & 130.9 & 10 & 404.4 & 234.9 & 130.9 \\
\hline & & 100 & 341.7 & 228.1 & 130.9 \\
\hline & & 1000 & 276.3 & 151.6 & 130.9 \\
\hline & & 10000 & 210.8 & 103.4 & 103.4 \\
\hline & & 100000 & 149.5 & 71.0 & 71.0 \\
\hline & & 525600 & 117.1 & 57.9 & 57.9 \\
\hline
\end{tabular}




\section{Appendix C - Creep-Fatigue Design Curves}

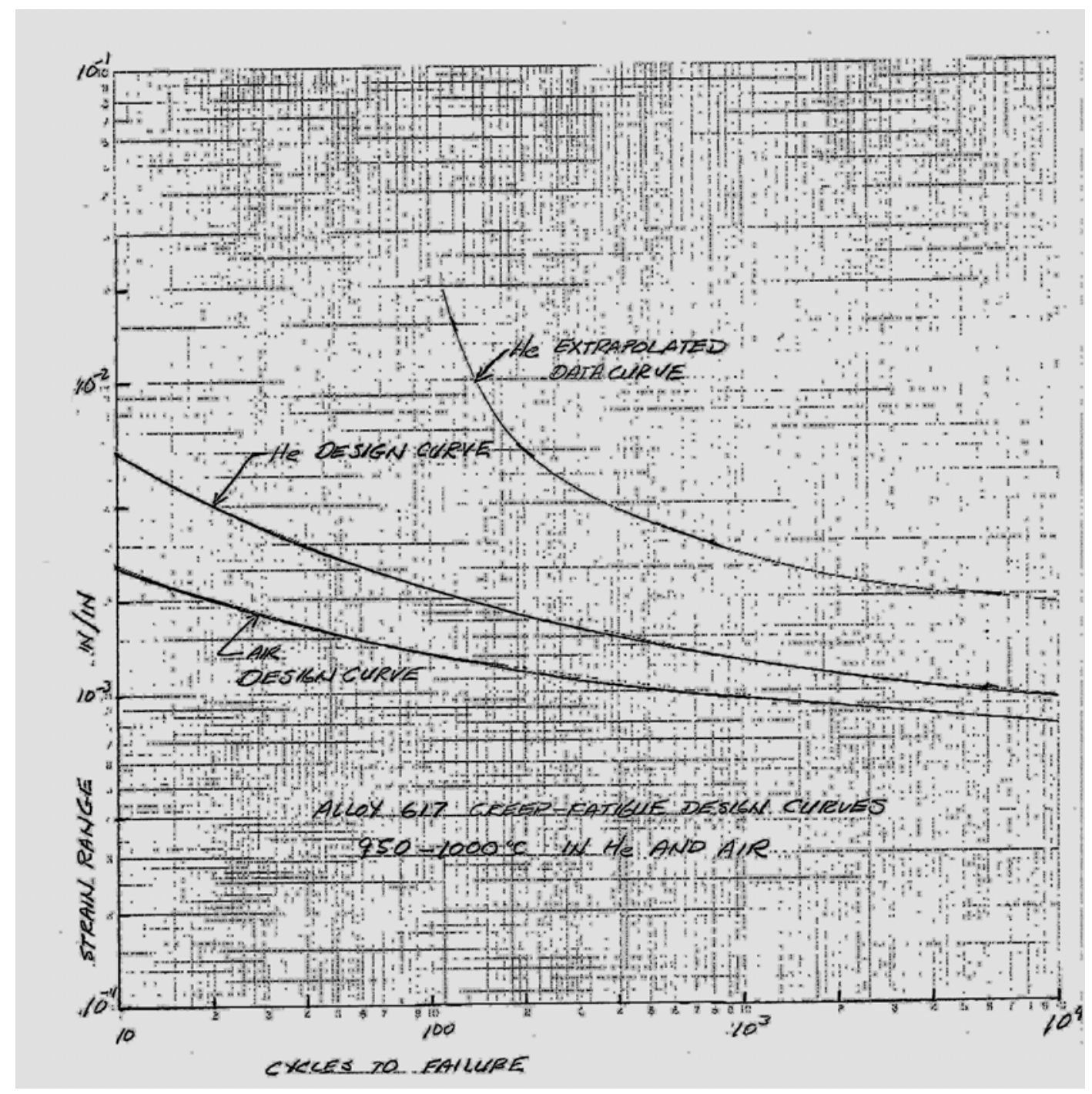

Figure C-1 Creep-Fatigue Design Curve for Alloy 617 (950-1000 $\left.{ }^{\circ} \mathrm{C}\right)$ 


\section{Appendix D - Isochronous Stress/Strain Curves}

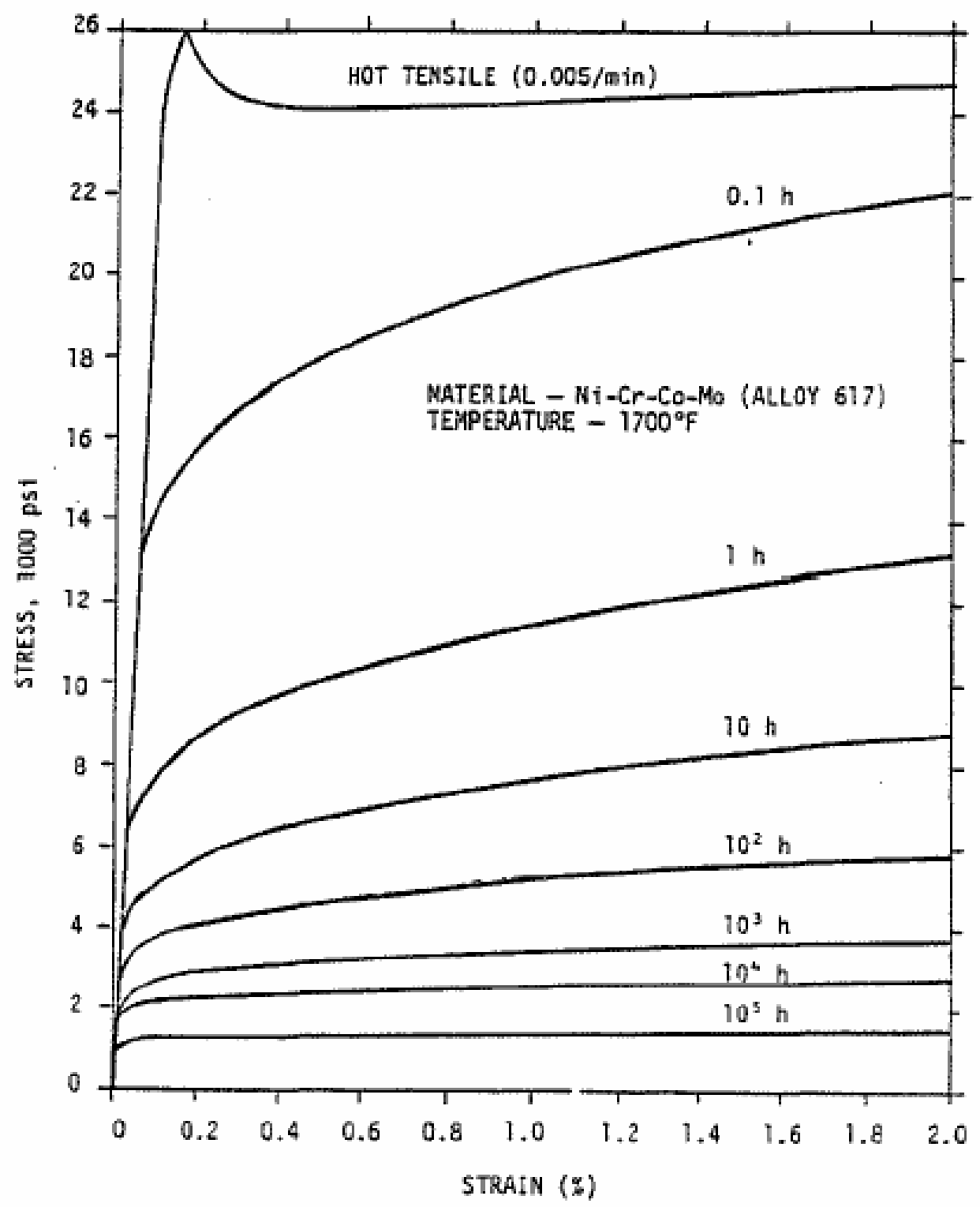

Figure D-1 Average Isochronous Stress-Strain Curves for $927^{\circ} \mathrm{C}\left(1700^{\circ} \mathrm{F}\right)$

Note, the units for this plot are not in SI units. 


\section{Appendix D - Isochronous Stress/Strain Curves (continued)}

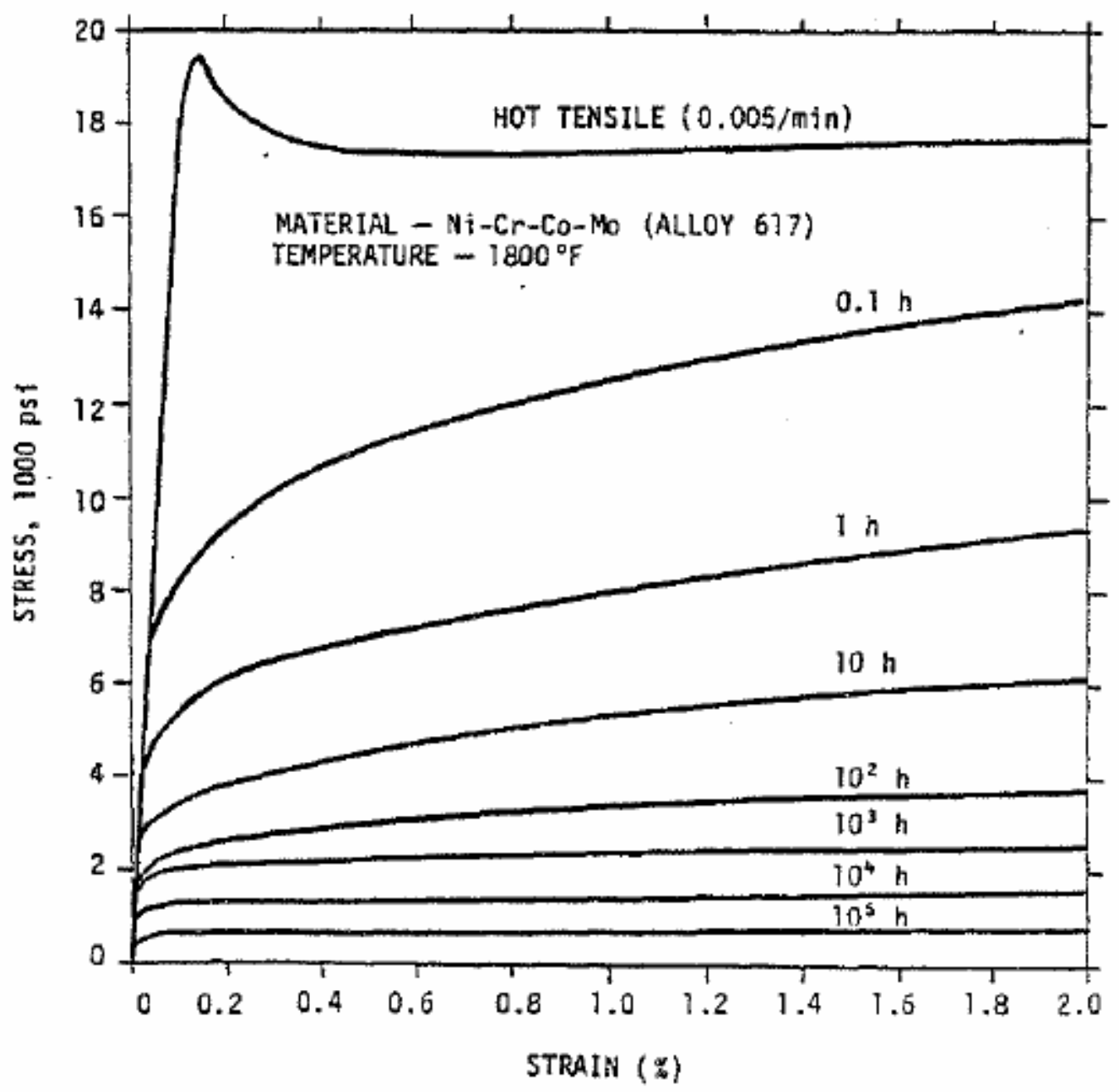

Figure D-2 Average Isochronous Stress-Strain Curves for $982^{\circ} \mathrm{C}\left(1800^{\circ} \mathrm{F}\right)$ Note, the units for this plot are not in SI units. 